\title{
Las aljamas mudéjares castellanas en el siglo XV: redes de poder y conflictos internos
}

\author{
Ana Echevarría Arsuaga *
}

\begin{abstract}
RESUMEN
Este trabajo pretende ofrecer una nueva propuesta de sistematización de las aljamas mudéjares castellanas teniendo en cuenta el tipo de jurisdicción cristiana que se establecia sobre ellas. La intromisión de las autoridades cristianas castellanas en un entramado de poder ejercido por una serie de familias mudéjares, que ocupaban los principales cargos de las aljamas, dio lugar a una serie de conflictos que muchas veces tuvo que solucionar la autoridad real, como queda ejemplificado en el caso de
\end{abstract} ABSTRACT

This contribution offers a new approach to the organization of Castilian Mudejar aljamas, considering the kind of Christian legal status which was conferred on them. The participation of Christian officials in a network of influences controlled by a number of Mudejar families - who enjoyed the best positions in the aljamas- gave way to a series of conflicts which were solved by the King, as shown in the case of Segovia.

Segovia.

Aljama, en la Baja Edad Media, es el término que pasa a designar la congregación o comunidad de los musulmanes o judíos vasallos de una autoridad cristiana, y de forma más reducida, el consejo o junta de principales y ancianos que ostentaban los oficios rectores del grupo. Al mismo tiempo que funcionaba como célula articuladora de los musulmanes con su autonomia jurídica propia, la aljama servía a la monarquía para controlar a los mudéjares a través de un interlocutor colectivo y, sobre todo, para gestionar a través de ella los impuestos de este grupo. Durante el siglo xv, tanto las fuentes cronísticas como las fiscales permiten adivinar una época de florecimiento

* U.N.E.D. 
de las aljamas mudéjares castellanas. Sus miembros ocupan un sector importante de las industrias urbanas, realizan transacciones comerciales, ejercen la medicina y están a cargo de ciertos transportes que unen zonas mal comunicadas de la Meseta. Lejos de tratarse de grupos totalmente marginados y recluidos en las morerías, los mudéjares de la primera mitad de siglo se nos muestran como grupos activos en la economía y la vida social castellana. Eso no quiere decir que no se produjesen intentos de minar sus privilegios, como el conocido Ordenamiento de 1412, pero en general puede hablarse todavía de una situación de relativa convivencia. En esta etapa, los avatares de la población musulmana se asemejan bastante a los de la cristiana, sometidas ambas a una época de tensiones sociales y guerras civiles.

Todavía no se ha elaborado ninguna sistematización de las aljamas de mudéjares en los reinos de la Península Ibérica para sus distintos periodos debido, sobre todo, a la falta de documentación interna de estas comunidades y a la imprecisión de los datos demográficos para la mayor parte de la Edad Media 1 . A falta de estos dos tipos de fuentes nuestros esfuerzos deben dirigirse, pues, a otro tipo de aproximación al problema de la organización de las comunidades mudéjares. Asimismo, su relación con las autoridades cristianas nos puede ayudar a entender mejor la organización e importancia relativa de la comunidad mudéjar.

Una posibilidad es estudiar la organización jerárquica en el territorio de las aljamas de las ciudades castellanas y de qué manera se inscribe el poder de los alcaldes mayores y de los alcaldes locales en las redes urbanas $^{2}$. Las aljamas, en tanto que situadas en ciudades de mayor o menor importancia ${ }^{3}$, eran las sedes de las circunscripciones judiciales que habían sobrevivido al periodo islámico. Debido a las transformaciones impuestas por el dominio cristiano, muchas de las sedes de la judicatura islámica habían ido perdiendo importancia (como Córdoba), y se habían inscrito en la órbita de otras aljamas mayores (en este caso, Sevilla). Las aljamas ur-

- No podemos dejar de mencionar a este respecto los extensos trabajos de LaDERo QuESADA, M. A., Los mudéjares de Castilla en tiempo de /sabel I, Valladolid, 1969; "Los mudéjares de Castilla en la Baja Edad Media", Actas del I Simposio Internacional de Mudejarismo, Teruel, 1981, pp. 349 390 y del mismo autor «Los mudéjares en los reinos de la Corona de Castilla. Estado actual de su estudio", Actas del III Simposio Internacional de Mudejarismo, Teruel, 1986, pp. 5-20, refundidos en el volumen Los mudéjares de Castilla y otros estudios de historia medieval andaluza, Granada, 1989, pp. 11-99.

2 La explicación de la supervivencia de los cargos de la alcaldía mayor de los moros la he realizado en otro artículo de próxima aparición que complementa a éste: «De cadí a alcalde mayor. La élite judicial mudéjar en el siglo XV", al-Qantara, (2002) (en prensa).

3 Calero Secall, M. I., "La justicia. Cadies y otros magistrados", en El reino nazari de Granada, Historia de España Menéndez Pidal, (coord. M. J. Viguera), Madrid, 2000, VIII.3, pp. 387-390 hace un interesante estudios de las sedes judiciales para Granada que, por el momento, es imposible de realizar para el reino de Castilla. 
banas y sus autoridades, a su vez, controlaban un territorio rural más o menos extenso en el que existía mano de obra musulmana.

La composición y organización de los cargos de la aljama es fundamental para definir su importancia dentro del reino, pero su estudio está todavía por hacer. Las aljamas más pequeñas, con un consejo reducido que podía llegar a estar compuesto por un solo alfaquí, solían consultar a otras más grandes para asuntos diversos. En una aljama grande había al menos un alcalde mayor, cuatro o cinco jurados o viejos, un zalmedina, un alamín y un alfaquí que podía actuar a la vez de escribano y notario. La articulación de las redes de influencia entre las aljamas de primer orden y lo que podríamos considerar "aljamas dependientes" se encuentra ligada a las familias de la élite mudéjar y facilita la comprensión de las relaciones dentro de la comunidad musulmana de los reinos cristianos peninsulares.

En primer lugar, es necesario emprender la identificación de los musulmanes que desempeñaban estos cargos, de sus familias, y de las redes de clientela o solidaridad familiar ('asābiyya) que los unian. Gracias a los numerosos estudios parciales que se están llevando a cabo en aljamas individualizadas, nos encontramos en disposición de empezar a descubrir quiénes eran estos personajes, y de qué manera llevaban las riendas de su comunidad. Como hemos defendido reiteradas veces Molénat y yo misma ${ }^{4}$, no podemos hablar de un grupo indiferenciado de mudéjares dedicados a las tareas del campo y a modestos oficios urbanos. Si la familia de los Xarafí constituye una verdadera élite urbana en Toledo y la de los Belvís en Guadalajara, el descubrimiento y estudio de nuevos documentos en archivos locales proporcionará sin duda una perspectiva distinta de las élites urbanas mudéjares en los próximos años.

El primer paso para poder analizar las redes de articulación de las aljamas mudéjares dentro del reino castellano podría ser una división según la jurisdicción cristiana de la que dependen, es decir, si eran aljamas de realengo, de un miembro de la familia real, o pertenecían a un señorío nobiliario -basándonos en la clasificación propuesta por Ferrer i Mallol para la

4 Molenat, J. P., "Une famille de l'élite mudéjare de la Couronne de Castille: les Xarafi de Tolède et Alcalá de Henares", Mélanges Louis Cardaillac. Éfudes réunies et préfacées par Abdeljelil Temimi, Zaghouan, 1995, 2, pp. 765-772; “À propos d'Abrahen Xarafí: les alcaldes mayores de los moros de Castille au temps des Rois Catholiques", en Actas del VII Simposio Internacional de Mudejarismo, Teruel, 1999, pp. 175-184. También sus artículos aLa question de l'élite mudéjare dans la Péninsule Ibérique médiévale", en el coloquio Élites e redes clientelares na ldade Média. Problemas metodológicos, Universidad de Évora, 15-16 juin 2000 y “Alcaldes et alcaldes mayores de moros de Castille au xve siècle" (en prensa). Agradezco al Dr. Molénat que me haya permitido consultar sus artículos antes de la publicación. También Echevaraía, A., "Mudéjares y moriscos", en El reino nazarí de Granada, Historia de España Menéndez Pidal, (coord. M. J. Viguera), Madrid, 2000, vol. VIII.4, pp. 367-440. 
gobernación de Orihuela ${ }^{5}$. Además hemos establecido otras dos categorías: las de jurisdicción eclesiástica, y las pertenecientes a alguna orden militar. Hay que tener en cuenta que el señorío puede pasar de unos a otros poderes a lo largo del tiempo, por lo que procuraremos ajustarnos en lo posible a los reinados de Juan II y Enrique IV, que son los que corresponden a los documentos que hemos estudiado. La distribución ${ }^{6}$, presentada en el mapa adjunto, que en ningún momento pretende ser definitiva, ayuda a clarificar los ámbitos de poder que cada uno de estos grupos cristianos podía ejercer sobre las comunidades musulmanas de la Península.

Al nombrar a los alcaldes mayores del reino y locales, el rey podía actuar directamente sobre las aljamas de realengo, situadas normalmente en las ciudades más grandes del reino y sedes habituales de la corte, como Ávila, Segovia, Burgos, Palencia, Madrigal, Tordesillas, Toro, Medina del Campo, Salamanca, Valladolid, Toledo, Madrid o Sevilla. Aun así, se producen a menudo enfrentamientos entre el rey y los concejos por controlar las aljamas de realengo, pues éstos últimos pretendían que las aljamas les quedasen subordinadas en los asuntos civiles 7 . Cuanto más asimilada está la población mudéjar de una zona o ciudad, y más específico es su peso económico en un sector de la producción determinado, más importante es afianzar este control sobre ella. En el espacio físico, este tipo de control se demostraba, por ejemplo, cuando las reuniones que tenían lugar normalmente en la mezquita principal de la morería o en la plaza del pueblo, se celebraban en una iglesia o en la "plaza de los cristianos", para unirse al concejo y a la aljama de los judíos ${ }^{8}$.

5 FERRER I MALLOL, M. T., Les aljames sarraines de la governació d'Oriola en el segle XIV, Barcelona, 1988, pp. 6-43.

6 Para elaborar este mapa se han consultado además de los mencionados estudios de Ladero Quesada, las siguientes obras: Gómez Vozmediano, M., Mudéjares y moriscos en el Campo de Calatrava, Ciudad Real, 2000; GonzÁleZ JIMÉNEZ, M., "Los mudéjares andaluces (ss. XIII-XV)", Actas del V Coloquio internacional de Historia Medieval de Andalucía, Córdoba, 1988, pp. 537-550; TAPIA SANCHEZ, S. de, La comunidad inorisca de Ávila, Salamanca, 1991; LUIS LOPEZ, C., La comunidad de villa y tierra de Piedrahita en el tránsito de la Edad Media a la Modema, Ávila, 1987; Cantera Montenegro, E., "Los mudéjares en el marco de la sociedad riojana bajomedieval», Actas del III Simposio Internacional de Mudejarismo, pp. 21-38; RodRiGUEZ LLOPIS, M., «Población y fiscalidad en las comunidades mudéjares del reino de Murcia (s. XV)". Actas del III Simposio Internacional de Mudejarismo, pp. 39-53; EchaGūE Burgos, J. J., La Corona y Segovia en tiempos de Enrique IV (1440-1474), Segovia, 1993; LAVADo PARADINAS, P., "Morerías castellano-leonesas", Actas del VI Simposio Internacional de Mudejarismo, Teruel, 1996, pp. 719-751; MAaSILLA PASCUAL, S., "Los moriscos de señorío eclesiestico en el reino de Murcia (́siglos XVI-XVII)", Actas del III Simposio Internacional de Mudejarismo, pp. 87-92; PORRAS ARBOLEDAS, P. A., La Orden de Santiago en el siglo XV. La provincia de Castilla, Jaén, 1997; Rodriguez BLAnco, D., La Orden de Santiago en Extremadura (siglos XIV y XV), Badajoz, 1985; TORRES FONTES, J., "Los mudéjares murcianos en la Edad Media", Actas del III Simposio Internacional de Mudejarismo, pp. 55-66; Yelo TEMPLADO, A., "Los vasallos mudéjares de la Orden de Santiago en el reino de Murcia (ss. XIV-XV)", en Las Ordenes Miltares en la Península durante la Edad Media, Madrid-Barcelona, 1981.

7 Miguel, J. C. de, La comunidad mudéjar de Madrid, Madrid, 1989, pp. 39-44.

8 Garcia Marco, F. J., Las comunidades mudejares de Calatayud en el siglo xV, Calatayud, 1993, pp. 341-369, cita la mayor parte de los lugares de reunión de las aljamas de la comarca de Calatayud. 


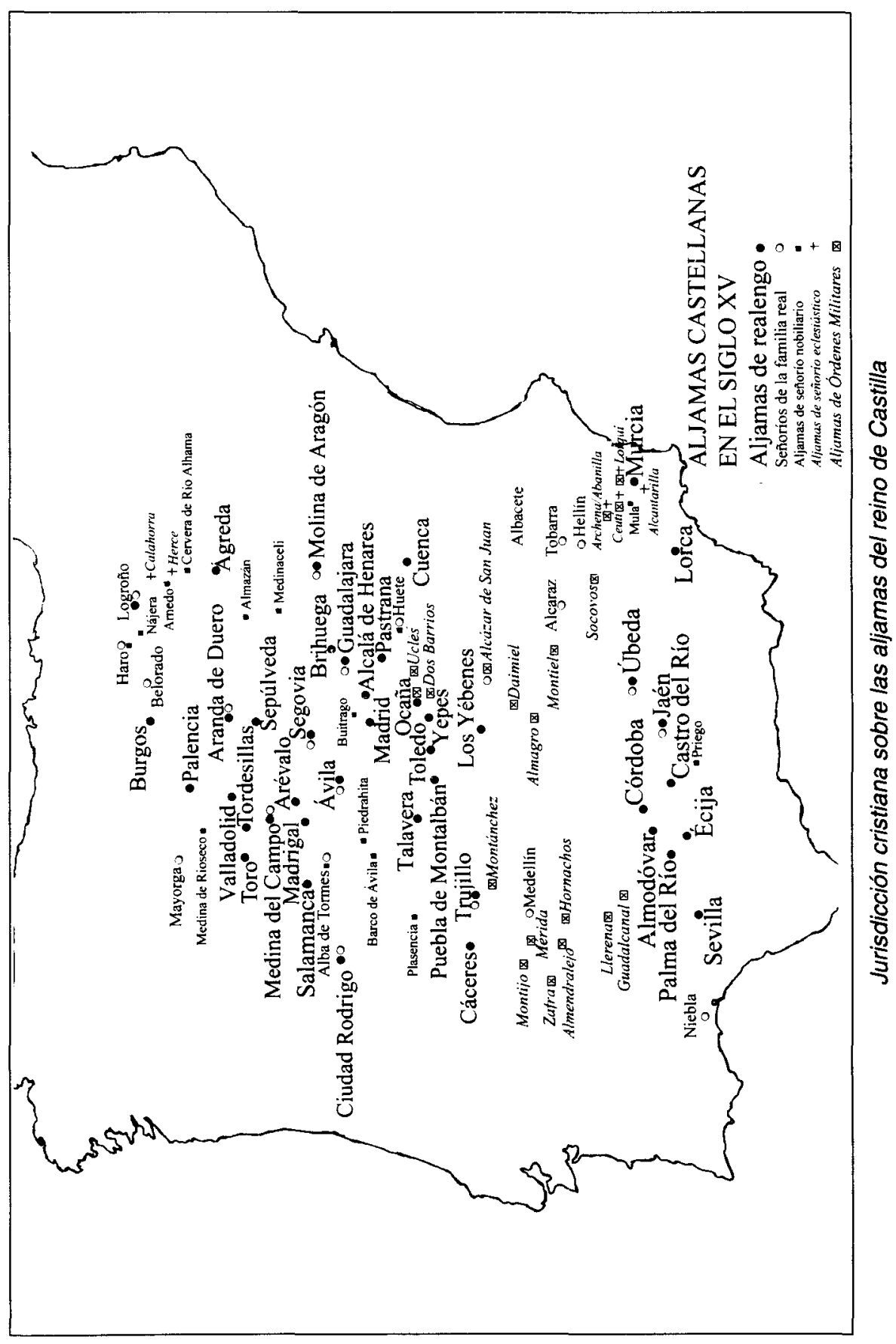


Indudablemente, el rey tenía también la última palabra en las aljamas de los señorios eclesiásticos (obispados y monasterios, para los que a menudo trabajaban los mudéjares), aunque en ellos eran frecuentes los conflictos entre distintas jurisdicciones por rentas procedentes de las mismas aljamas, como las que enfrentaron al obispado de Cartagena con las órdenes militares de San Juan, por Archena, o Calatrava, en el caso de Abanilla. A pesar de la injerencia de los cortesanos en el nombramiento de altos cargos mudéjares, la autoridad real y del consejo podía ejercerse sin discusión en estos lugares.

Muy distinta era la situación en los otros casos de jurisdicción cristiana: señoríos de las Órdenes Militares, señoríos pertenecientes a la familia real y señoríos nobiliarios. En el primer caso, los extensos señoríos de las Órdenes, sobre todo al sur del Sistema Central, contaban con una elevada población de mudéjares, potenciada desde los mismos maestrazgos. Como ya se ha señalado reiteradamente, la lucha por los recursos de las aljamas, en este caso humanos, significó para éstas a la vez una presión creciente por parte de los señores correspondientes, y una posibilidad de escapar a las peores condiciones mediante la huida a otro señorío, o al menos el recurso a la amenaza al señor con una posible huída. De esta manera, los mudéjares se convierten en moneda de cambio en el enfrentamiento de los intereses de la nobleza y la monarquía, el clero secular y las Órdenes Militares.

La dispersión del patrimonio de la monarquía entre los miembros de la familia real, en forma de señoríos, es un fenómeno importante desde el siglo XIII, pero especialmente conflictivo en el XV, cuando personajes como Juan de Navarra poseían durante el reinado de Juan II un patrimonio territorial casi tan importante como el del propio monarca. Estos señorios solian volver a la corona tras la muerte del beneficiario, por lo que podemos considerarlos a medio camino entre las propiedades de realengo y los señoríos nobiliarios. Pero en tanto que nobles, los miembros de la familia real podian tener también señoríos hereditarios, y en ese caso podían ejercer un control más estrecho sobre sus aljamas. Por ejemplo, el infante don Enrique heredó de su madre Leonor de Alburquerque en 1415 las villas con aljama de Medellín, Belorado y Haro; Juan de Navarra, al heredar a su padre Fernando de Antequera, poseyó Mayorga y Medina del Campo, entre otras. Las donaciones que realizó el propio Juan II a su hijo, el futuro Enrique IV, nos dan idea de la amplitud del poder principesco sobre la comunidad mudéjar entre 1440 y 1450 . Al lado de semejante patrimonio, el que la princesa Isabel recibió en 1468 por el tratado de los Toros de Guisando resulta incluso moderado: entre sus ciudades se contaban las aljamas de Ávila, Huete, Úbeda, Alcázar de San Juan, Molina, Medina del Campo, Escalona y Aranda de Duero. Es en este caso en el que hemos observado la arrogación de la capacidad de nombrar alcaldes mayo- 
res locales por parte de Isabel, haciendo uso de unas prerrogativas que no le correspondian 9 .

La protección ofrecida por diversos miembros del estamento nobiliario dio lugar a la concentración de numerosos mudéjares en villas de señorio, insuficientemente estudiadas en el reino de Castilla, sobre todo en el aspecto jurídico. Desconocemos, por tanto, la capacidad de actuación de los nobles en cuanto a ejercer presiones sobre alcaldes de aljamas concretas, a no ser su intervención personal en el nombramiento de los alcaldes mayores del reino de Castilla, como en el caso concreto de los Mendoza.

En general, podemos decir a partir del estado actual de nuestros conocimientos que el marco legal de referencia para los mudéjares seguía siendo en el siglo $x v$ dictado por el rey, sin importar a qué jurisdicción pertenecieran los musulmanes en cuestión. Las ordenanzas de Murcia (1411) y el ordenamiento de Valladolid sobre moros y judíos (1412), intentaron prohibir los jueces particulares o alcaldes mayores de las aljamas, para ser sustituidos por los jueces locales cristianos (alcaídes). También los impuestos y su distribución pasarian a ser de atribución real, y no de las propias aljamas ${ }^{10}$. Como han señalado varios autores, las ordenanzas de 1412 se aplicaron muy limitadamente, y su revocación generalizada en 1418 limitó su impacto que, sin embargo, podía resultar peligroso para las aljamas a largo plazo.

A partir de ese momento se generaron nuevas situaciones: en algunas ciudades los musulmanes prefirieron ser juzgados por un alcalde del concejo, antes que por el alcalde de la aljama, y renunciaron a su privilegio de tener jueces propios. Otras veces fueron los propios particulares los que acudieron al rey para pedir que se les permitiera acudir a los alcaldes locales o a la audiencia para plantear casos que estimaban que el alcalde mayor de los moros no iba a resolver con ecuanimidad, debido a su entorno personal. Finalmente, el nombramiento de jueces cristianos para ejercer como alcaldes de moros, cristianos y judíos, se intensificó en un momento dado de las luchas internas entre Enrique IV y los nobles ${ }^{11 .}$

La sustitución del alcalde mayor de las aljamas por jueces locales del concejo pudo ser voluntaria u obligada por las presiones del propio concejo. Sabemos que éste representaba a menudo a las aljamas de moros y judíos ante el rey si el número de habitantes de estas comunidades tenía una importan-

9 Ver nota 2.

10 Fernandez y GonzAlez, F., Estado social y político de los mudéjares de Castilla (Madrid, 1866/1985), pp. 401-402. Ver también ECheVARRIA, A., “Política y religión frente al Isiam: la evolución de la legislación real castellana sobre musulmanes en el siglo xv", Qurtuba 4 (1999), pp. 45-72.

11 También en Aragón llegó a ocurrir que las aljamas de Elche, Játiva, Aranda, Orihuela o Crevillente tuvieron cadies cristianos. BosweLL, J., The Royal Treasure. Muslim Communities under the Crown of Aragon in the Fourteenth Century, New Haven, 1977, pp. 78-87. 
cia numérica o económica determinante para los intereses ciudadanos. No sería extraño, por lo tanto, que las aljamas depositaran también en ellos su capacidad jurídica. El caso más evidente es el de Toledo y Segovia, dos ciudades importantísimas de realengo que en algún momento indeterminado del siglo $\mathrm{XV}$ renuncian a la jurisdicción islámica. Creemos que ambos casos están relacionados, puesto que Segovia era una de las aljamas que dependía del alcalde mayor de Toledo, Mahomad al-Qaysī, en torno a 1420. Cuando dos importantes familias castellanas de mudéjares, los Belvís de Guadalajara y los Xarafí de Toledo, intentaron hacerse con el cargo de alcalde mayor del reino, tuvieron problemas para ser aceptados en estas ciudades, y ambas adujeron la renuncia de su jurisdicción en los tribunales cristianos.

El caso de Segovia es particularmente interesante por la cantidad de documentación que se ha conservado y porque durante el reinado de Enrique IV actuó prácticamente como capital del reino. Enrique, aún príncipe, ya controlaba la ciudad en 1441, y la dona a Juan Pacheco, marqués de Villena, de forma hereditaria, permitiéndole nombrar al alcaide y oficiales de su fortaleza, pero o bien se reserva la aplicación de la justicia para sí mismo, o se la concede por muy breve tiempo. De hecho, hacia 1453 «el príncipe controlaba la administración de justicia de la ciudad hasta el punto de hacer sobreseer injustamente ciertos casos judiciales" 12.

La ciudad sufría desórdenes casi continuados, pues entre 1442-46 fue el centro de la oposición armada del príncipe a su padre Juan II, y entre 1451-53 estuvo agitada por las luchas entre bandos ciudadanos y por la oposición entre el príncipe y el concejo. No sabemos con precisión si fue éste el momento - citado por todas las fuentes-, en que el concejo se hizo con el apoyo de la aljama mudéjar y asumió la jurisdicción sobre ellos, probablemente a cambio de ejercer una cierta protección frente al príncipe, quien a partir de 1454 será nombrado rey, pero no modificará su política de intervención directa en Segovia y su alfoz. Los vecinos mudéjares de Segovia manifiestan repetidas veces, la última en 1492, que

«la dicha aljama e vesinos moradores della de diez e veynte e treynta e quarenta e çinco años e mas tiempo a esta parte que syenpre la dicha aljama e vesinos e moradores della avian estado e estavan en paçifica posesyon de no tener ni obedeçer alcalde ninguno mayor de las aljamas de Castilla salvo la nuestra justiçia hordinaria, que avia seydo e hera de la dicha çibdad (...) e que el señor rey don Enrique nuestro hermano que sancta gloria aya seyendo ynformado que a cabsa de aver alcalde mayor de moros en la dicha aljama oviera en ella en los tienpos pasados muy grandes diferencias e debates e quistiones $e$ muertes de onbres entre los moros della de la qual cabsa fuera perdimiento de

12 Echagüe Burgos, J. J., op. cit., pp. 56-59. 
mas de treynta vesinos a la dicha aljama, de lo qual el dicho señor rey don Enrique por faser bien e merçed a la dicha aljama mandara al alcalde moro que a la sazon hera que non usase nin exerçiese el dicho ofiçio de alcaldia mayor el nin otro por el en la dicha çibdad. E que nos, conformandonos con lo quel dicho señor rey don Enrique ovo mandado e ynformados sobre aquello lo que cumplia a nuestro serviçio, mandaramos dar una provision a la dicha aljama por la qual diz les mandamos guardar el uso en que avia estado de non tener aicalde mayor sobre sy salvo la nuestra justiçia hordinaria de la dicha çibdad» 13.

Ignoramos cuándo se produjo esta transferencia de la jurisdicción del cadí o alcalde a la de las justicias cristianas, pero algunos datos pueden ayudar a aproximar la fecha. En primer lugar, Segovia tenía un alcalde delegado de Mahomad al-Qaysī en torno a 1418, maestre Yça, identificado con Yça Gidelli por Torres Fontes. Si aceptamos esta identificación, y puesto que la inscripción del alcázar de Segovia que Wiegers relaciona con Yça Gidelli habla del «maestro Xadel, alcalde" en 1456, podemos suponer que en esa fecha todavía ejercia este oficio en la aljama de Segovia. Esta fecha coincide con la precipitada vuelta de Yça Gidelli a Castilla desde Ayton (en Saboya, Italia), donde estaba traduciendo el Corán para Juan de Segovia ${ }^{14}$. Además, sabemos que la muerte de Mahomad al-Qaysī, su superior, se produjo antes de 1458.

Que los disturbios y la muerte de varios hombres estén relacionados con la alcaldía de Yça Gidelli parece evidente. No sólo su hermano no pudo acudir a Aytón, tal como había prometido a Juan de Segovia, sino que parte de su familia tuvo que huir de Segovia para refugiarse en el reino de Granada ${ }^{15}$, de donde no regresarian hasta 1480. La huida de la familia y de otras de las principales de la ciudad ${ }^{16}$ pudo ser una de las causas de la pérdida de al menos treinta vecinos, lo que pudo llevar a la despoblación de la morería, tal como explica la aljama a los Reyes Católicos más tarde. La huída de los no-

13 ARCV, RCE, 39-6, f. 2r-v (ver apéndice). La cursiva es de la autora. Hemos incluido esta relación por ser la más larga, pero la misma justificación aparece en el nombramiento de maestre Lope como alcalde de la aljama segoviana, AGS, RGS, febrero, 1480, 259, ed. TorRES FontES, J., «El alcalde mayor de las aljamas de moros del reino de Castilla", Anuario de Historia del Derecho Español (1962), pp. 131-182. Cit. AsEnjo GonzAlez, Segovia, la ciudad y su tierra a fines del medievo, Segovia, 1986, p. 338. Un último privilegio de los Reyes Católicos para que la aljama pueda acudir a la justicia ordinaria zanja la cuestión: AGS, RGS, marzo 1492, 122, ed. LADERO QueSADA, M. A., Los mudéjares en tiempo de Isabel I, pp. 189-191.

14 Cabanelas Rodriguez, D., Juan de Segovia y el problema islámico, Madrid, 1952, pp. 290, 292; Wiegers, G., Islamic Literature in Spanish and Aljamiado. Yca of Segovia, his Antecedents and Successors. Leiden, 1994, p. 148.

15 Juan de Segovia lo atribuye al miedo por atravesar territorios cristianos, a pesar del salvoconducto del duque de Saboya, pero parece más lógico atribuirlo a los problemas internos de la aljama. Cabanelas Rodriguez, D., op. cit., p. 292. Sobre la vuelta de Granada, ver AGS, RGS, febrero 1480, 56 (ver apéndice). Cit. WIEGERS, G., Islamic literature..., p. 80.

16 Se hace referencia a estos hechos en AGS, RGS, agosto 1490,82 , retrotrayéndolod en cincuenta años. 
tables debió ocasionar graves trastornos económicos a la aljama, de ahí el interés de los monarcas en la vuelta de los mudéjares huidos y la insistencia en que regresaran con "sus bienes y haciendas" y toda la gente de su casa.

Efectivamente, parece que Segovia queda desprovista de alcalde mayor de la aljama entre 1456 y 1474 , a juzgar por un documento en el que el rey Enrique IV absuelve al alfaqui Abseyt de la muerte del judío Lesar Albohacén, previa vista del caso por el comendador Avellaneda ${ }^{17}$ y después por los justicias Rodrigo de Peñalosa, Nuño González, Diego Díaz Tello y Diego Espinar ${ }^{18}$. Un alfaquí sólo podría ser juzgado por su superior, el alcalde mayor de la ciudad, o en su caso por el alcalde mayor de todas las aljamas. Sin embargo será un tribunal formado por miembros exclusivamente cristianos el que decida su causa. No es de extrañar que la aljama segoviana hiciera valer constantemente su carta de merced en la que se les permitía acudir a los alcaldes cristianos, presentando esta carencia como un beneficio deseado por la comunidad para evitar banderías internas.

Durante el reinado de los Reyes Católicos, los segovianos insistirán en su actitud, frente a las exigencias de los alcaldes mayores de Madrid, maestre Lope y maestre Farax, y del alcalde mayor de las aljamas de Castilla Abrahen Xarafí, también alcalde mayor de Toledo, y su delegado Abrahen Redomero, alcalde mayor de Valladolid ${ }^{19}$. Esta lucha por el control de Segovia refleja perfectamente las redes de influencia y los intentos de expandir el área de jurisdicción de los máximos representantes de la comunidad mudéjar en Castilla.

\section{APÉNDICE}

1480, febrero, 21. Toledo.

Carta de salvoconducto de los Reyes Católicos a Omar alfaquí y Mahomad calderero para que vayan al reino de Granada a traer a Castilla a su familia y a los mudéjares de Segovia que deseen regresar a la ciudaq. Archivo General de Simancas, Registro General del Sello, febrero 1480, 56.

17 Probablemente alcaide de la fortaleza en delegación de Gonzalo Chacón. Fue comendador de Carrizosa, Manjarrés y del Hospital de Alarcón de la Orden de Santiago (1468-80), a la que también pertenecía Chacón, que a su vez era alcaide de Segovia. Porras Arboledas, P. A., op. cit., pp. 327,329 .

18 AGS, RGS, agosto 1476, f. 569.

19 Sobre todos los pleitos que generan estas luchas por el poder en la comunidad mudéjar, ver MOLÉnAT, J.P., “À propos d'Abrahen Xarafí...", pp. 175-184, y EchEVARRía, A., "De cadi a alcalde mayor. La élite judicial mudéjar en el siglo XV”, al-Qantara, (2002) (en prensa). 


\section{Omar alfaqui e Mahomad calderero, vesinos de Segovia.}

Seguro e salvoconducto que puedan entrar seguros en tierra de moros a traer e sacar de alla çiertos moros e moras que se pasaron de Castilla en tienpo de las guerras e movimientos pasados.

Don Fernando e doña Ysabel, etc. Por quanto por parte de vos Omar alfaqui de la çibdad de Segovia e Mahomad calderero moro vesino de la muy noble çibdad de Segovia, nos es fecha relaçion que vosotros tenedes en el regno de Granada dos fijas e querriades entrar en el dicho regno e las sacar e traer a estos nuestros regnos, e que asimismo al tienpo de los movimientos en estos nuestros reynos acaesçidos algunos moros naturales dellos se fueron con sus mugeres e fijos e nietos e criados e otras personas con ellos a bevir al dicho regno de Granada a cabsa de los dichos movimientos, e que agora ellos se querrian venir a bevir a estos nuestros regnos con sus mugeres e fijos e nietos e criados e con sus faciendas e bienes, e que se temen e reçelan que si ellos entrasen en estos nuestros reynos sin nuestra linçençia serian presos o cativos o enbargados o les seria fecho otro mal e daño o desaguisado alguno en sus personas e bienes, e nos suplicastes e pedistes por merçed vos mandasemos dar nuestra carta de seguro e salvoconducto para vos, los dichos Omar alfaqui e Mahomad calderero pudiesedes entrar libre e seguramente en el dicho regno por qualquier de los puertos destos nuestros regnos e señorios e sacar las dichas vuestras fijas con sus fasiendas e bienes e los otros moros que con vos se quesieren venir con sus mugeres e fijos, nietos e criados e con fasiendas e bienes e pudiesedeis vos y ellos salir por qualquiera de los puertos destos nuestros regnos e señorios asy por mar como por tierra desde Lorca fasta Tarifa o por qualquier dellos que vos mas quesierdes. $E$ que erades prestos de dar fiança bastante de tornar a estos /f. $1 \mathrm{v} /$ nuestros regnos. E porque vos disteis fiança de mill doblas que tornariades a estos nuestros regnos e a la dicha çibdad desde oy dia de la data desta nuestra carta fasta çiento e veynte dias primeros seguientes, tovimoslo por bien e por la presente vos damos liçençia a vos e a los sobredichos moros que con vos venian para qu podades entrar por qualquier de los dichos puertos por mar o por tierra como dicho es, dentro de los dichos çiento e veynte dias primeros seguientes, vos damos nuestro seguro e salvoconduto por el dicho tienpo. E vos seguramos e prometemos por nuestra fee e palabra real como Rey e Reyna e señores naturales que durante el dicho tienpo que vos estovierdes en yr al dicho regno de Granada e venir a estos nuestros regnos vos e todos los moros que con vos quesieren venir con sus mugeres e fijos e nietos e criados e otras personas con sus bienes e fasiendas non seredes ni seran presos ni detenidos ni cativados ni enbargados ni feridos ni muertos, ni vos sean ni les seran tomados vuestros bienes ni suyos ni mercadoria ni las otras cosas que vos o ellos o qualquier de vos o dellos troxierdes a estos nuestros regnos, ni cosa alguna de lo vuestro ni 
de lo suyo, vosotros non sacando ni levando destos nuestros regnos cavallos ni armas ni las otras cosas por nos vedadas, e pagando de las mercaderias que levardes ellos o vos troxierdes los derechos acostumbrados. E por esta nuestra carta o por su traslado firmado de escrivano publico mandamos a los ynfantes, duques, prelados, condes, marqueses, ricosomes, maestres de las hordenes, priores, comendadores e subcomendadores, alcaydes de los castillos e casas fuertes e llanas e a los alcaldes e guardas e almoxarifes de los puertos de nuestros regnos que son fronterizos del regno de Granada e a los dichos exeas e alfaqueques e adalides e almogavares que son en la frontera, e a todos los conçejos e alcaldes, algosyles, regidores, cavalleros, escrivanos, ofiçiales e omes buenos de todas las çibdades e villas e logares de los nuestros regnos e señorios e a otras qualesquier personas nuestros vasallos e subditos e naturales de qualquier ley o estado, condiçion, preheminençia o dignidad que sean e a cada uno o qualquier de ellos a quien esta dicha nuestra carta fuere mostrada o el dicho su traslado signado como dicho es, que vos guarden e les guarden e fagan guardar e conplir este nuestro seguro e salvoconduto que nos e los sobredichos Omar alfaqui e el dicho Mahomad e a los moros que con ellos del dicho regno de Granada salieren e sus mugeres e /f. $2 r$ fijos e nietos e criados e bienes e fasiendas, que no sean ellos ni los que con ellos salieren por qualquier de los dichos puertos presos ni detenidos ni cativos ni enbargados ni feridos ni muertos ni les sea fecho otro mal ni daño ni desaguisado alguno durante el dicho tienpo. Lo qual vos sea e les sean todo asi guardado e conplido segund que en este nuestra carta se contiene, e que vos non vayan ni pasen ni consientan yr ni pasar contra el en manera alguna, ca nos por esta nuestra carta tomamos e reçebimos a vos los dichos Omar alfaqui e Mahomad e a vuestras fijas e a los otros moros que con vos del dicho regno salieren $e$ a sus mugeres e fijos e nietos e criados en nuestra guarda $e$ seguro e so nuestro amparo, e defendimiento real. $E$ los unos ni los otros non fagades ni fagan ende al por alguna manera so pena de la nuestra merçed e de privaçion de los ofiçios e confiscaçion de los bienes de los que lo contrario fesieren para la nuestra camara e fisco. E demas mandamos al ome que vos esta nuestra carta mostrare que vos enplase que parescades ante nos en la nuestra corte doquier que nos seamos del dia que vos enplasare fasta quinse dias primeros seguientes so la dicha pena so la qual mandamos a qualquier escrivano publico que para esto fuere llamado que de ende al que vos la mostrare testimonio sygnado de su sygno porque nos sepamos como se cumple nuestro mandado. Dada en la muy noble çibdad de Toledo a veynte un dias del mes de febrero, año del nasçimiento de Nuestro Señor Ihesuchristo de mill e quatroçientos e ochenta años. Yo el Rey. Yo la Reyna. Yo Alfonso de Avila, secretario del Rey ede la Reyna nuestros señores la fise escrevir por su mandado. $E$ en las espaldas, don Sancho Rodericus dotor, Johannes dotor, Andres dotor, Rodecanus dotor. Registrada Diego Sanches. 
2

1491, agosto, 30. Valladolid.

Carta ejecutoria de los Reyes Católicos sobre el pleito entre Abraham Xara-

fi por una parte, y la aljama de Segovia por otra, sobre la alcaldía de las aljamas de Castilla.

Archivo de la Real Chancillería de Valladolid, Reales Cartas Ejecutorias, caja 39-6.

Esecutoria. Madrid.

A pedimiento de don Abrahen Xarafi.

Sentado.

Don Fernando e doña Isabel, etc. A los del nuestro consejo e oydores de la nuestra abdiençia e alcaldes e alguaziles e otras justiçias de la nuestra casa e corte e chançelleria e a los corregidores e alcaldes e alguaziles, merinos e otros juezes e justiçias de la çibdad de Segovia e de todas las otras çibdades e villas e lugares de los nuestros reynos e señorios, asy a los que agora son como a los que seran de aqui adelante e a cada uno e qualquier de vos en vuestros lugares e juridiçiones a quien esta nuestra carta fuere mostrada o el traslado della sygnado de escrivano publico sacado con abtoridad de juez o de alcalde, salud e graçia.

Sepades que pleito paso e se trato en la nuestra corte e chancelleria ante nuestro presydente e oydores della entre don Abrahen Xarafi nuestro alcalde mayor de las aljamas de los moros destos nuestros reynos e su procurador en su nombre de la una parte e el aljama e omes buenos moros de la çibdad de Segovia de la otra, sobre razon que nos mandamos dar e dimos una nuestra carta esecutoria sellada con nuestro sello e librada de los nuestros oydores por la qual en efecto los dichos nuestro presydente e oydores pronunçiaron e declararon que don Abrahen Xarafi provara bien e conplidamente su demanda e replicaçiones e quel maestre Farax Beydeçi e don Farax de Belvis que con el litygaran sobre razon del dicho ofiçio de alcaldia mayor non provaran $/ f .1 \mathrm{v} / \mathrm{sus}$ esecuçiones e defensyones nin cosa alguna que les aprovechase e dieron $e$ pronunçiaron su yntençion por non provada e la del dicho don Abrahen Xarafi por bien e conplidamente provada, e devian condenar e condenaron a los dichos don Farax de Belvis e maestre Farax Beydeçi a que dende en adelante non usasen nin se entremetyesen a conoçer nin usar del dicho ofiçio de alcaldia mayor de las aljamas de los moros destos nuestros reynos nin se llamasen alcaldes mayores dellos, quedando al dicho don Farax de Belvis el alcaldia de los moros de la çibdad de Guadalajara, e que de las sentençias e mandamientos quel dicho don Farax de Belvis diese e pronunçiase de los pleitos que en la di- 
cha çibdad de Guadalajara conosçiese, que podiesen apelar e apelasen antel dicho don Abrahen Xarafy como ante alcalde mayor de las dichas aljamas, segund que esto e otras cosas mas largamente en la dicha nuestra carta esecutoria se contiene. Con la qual e con otras çiertas nuestras cartas por las quales en efeto fezimos merçed del dicho ofiçio del alcaldia mayor de los moros destos nuestros reynos al dicho don Abrahen Xarafi e enbiamos mandar a todas las aljamas de los moros de todas las çibdades, villas e lugares destos nuestros reynos e señorios que le toviesen e reçibiesen e toviesen por nuestro alcalde mayor de las dichas aljamas e usasen con el en el dicho ofiçio de alcaldia mayor o con quien su poder oviese segund mas largamente en las dichas nuestras cartas se contiene, con las quales e con la dicha nuestra carta esecutoria el dicho don Abrahen Xarafi requirio a la dicha /f. $2 \mathrm{r}$ / aljama que las obedeçiesen e conpliesen en todo y por todo segund que en ellas se contenia, e nos por ella se lo enbiavamos mandar e que sy lo asy fiziese facia bien. En otra manera protesto que su derecho que desia a salvo de los enplazar con las dichas (tachado: cartas para que paresçiesen) e la dicha aljama dixieron que ovedeçian e obedeçieron a las dichas nuestras cartas con la mayor reberençia que podian, e quanto al conplimiento dellas dixieron que fablando con la reverençia que devian, que non heran tenudos nin obligados a las conplir por la forma e manera que por ellas gelo enbiavamos mandar, e que en quanto a la dicha nuestra carta que se dirigia a la dicha aljama e a la juridiçion della por las razones seguientes: lo uno por que diz que la dicha nuestra carta non fuera senada con relaçion verdadera en quanto a la dicha aljama, e que sy a nos fuera fecha verdadera relaçion non proveyeramos del dicho ofiçio al dicho don Abrahen Xarafi, espeçialmente por que la juridiçion de la dicha aljama que nos sabiamos que la dicha aljama e vesinos moradores della de diez e veynte e treynta e quarenta e çinco años e mas tiempo a esta parte que syenpre la dicha aljama e vesinos e moradores della avian estado e estavan en paçifica posesyon de no tener ni obedeçer alcalde ninguno mayor de las aljamas de Castilla salvo la nuestra justiçia hordinaria, que avia seydo e hera de la dicha çibdad, e que nos non aviamos seydo ynformado e (sobrescrito: que no) nos fuera fecha (sobrescrito: verdadera) relaçion, e que el señor rey don Enrique nuestro hermano que sancta gloria aya seyendo ynformado que a cabsa de aver alcalde mayor de moros en la dicha aljama oviera en ella en los tienpos /f. $2 \mathrm{v} /$ pasados muy grandes diferençias e debates e quistiones e muertes de onbres entre los moros della de la qual cabsa fuera perdimiento de mas de treynta vesinos a la dicha aljama, de lo qual el dicho señor rey don Enrique por faser bien e merçed a la dicha aljama mandara al alcalde moro que a la sazon hera que non usase nin exerçiese el dicho ofiçio de alcaldia mayor el nin otro por el en la dicha çibdad. E que nos conformandonos como quel dicho señor rey don Enrique ovo mandado e ynformados sobre aquello lo que cumplia a nuestro serviçio mandaramos dar una provision a la dicha aljama por la qual diz les mandamos guardar el uso en que avia es- 
tado de non tener alcalde mayor sobre sy salvo la nuestra justiçia hordinaria de la dicha çibdad. E asymismo conoçiendo sobre nuestro serviçio nos (sobrescrito sobre tachado ilegible: ovo) suplicado la dicha çibdad e que con las tales provisiones se avia conservado la dicha aljama en toda paz e sosyego de la qual careçia sy no los oviesemos de apremiar a que veniesen de tener alcalde mayor moro alguno, lo qual sy a nos fuera fecha relaçion que creya que nos non mandariamos proveer al dicho Abrahen Xarafi de la dicha alcaldia en quanto tocava a la dicha aljama e vezinos e moradores della asy por lo que dicho avia a nos como por que segund los derechos de nuestros reynos la sentençia dada entrel dicho don Abrahen Xarafi los otros sus adversas partes en la dicha nuestra carta contenidos non podiera perjudicar rin parar perjuysio a la dicha su aljama con quel dicho Abrahen Xarafi non letigara; lo otro por quel reescripto. Ynpetrado contra otro reescripto o carta non faziendo /f. $3 \mathrm{r} /$ mençion del primero hora en sy ninguna. Lo otro porque nos oviesemos proveydo de la alcaldia al maestre Abrahen Redomero el qual les presentara otra carta (sobrescrito: nuestra) de merçed de la dicha alcaldia, e que por que las dichas cabsas susodichas como quiera que la dicha carta fuera obedeçida con la mayor reberençia que podian como carta e mandado nuestro, pero que non fuera conplida por que como dicho avian non heran obligados a conplir nin aquello hera nuestro serviçio, e que por que la non conplian fueran enplazados para ante nos segund que lo susodicho pusieran ante Cristoval Peres escrivano publico de la dicha çibdad, con el qual tenia pleito pendiente en el nuestro consejo estante, lo qual dezian que sy (repetido: sy) de todo ello nos fueramos ynformados non mandaramos dar nin dieramos la dicha nuestra carta nin los dichos nuestro asystente e oydores non dieran la dicha sentençia que dieran salvo heçebtando esta dicha aljama porque aquello non fuera nin hera nuestro serviçio y seria por las cabsas por nos dichas en nuestro desenviçio e disminuçion de la justiçia hordinaria de la dicha çibdad, con la qual avia estado e estava conservada en toda paz e sosyego desde los dichos tienpos aca que alcalde mayor non tenia, e que lo contrario seria despoblaçion nuestra e perdimiento de todos ellos. Por ende que suplicavan de la dicha manera para ante nos o personas a donde con derecho devian so cuya protesçion e anparo ponian a sus personas e bienes e sy testimonio /f. $3 \mathrm{v} /$ alguno el dicho Abrahen Xarafi pidiese le fuese dado con esta su respuesta e que non lo uno sy el otro por que dello nos fuesemos ynformados non mandasemos proveer nin dar provisyon alguna al dicho don Abrahen Xarafi non bien ynformados de la justiçia que tenian e que aquello davan por su respuesta al dicho requerimiento a ellos fecho por el dicho don Abrahen Xarafi con la dicha nuestra carta. E que sy testimonio alguno le fuese dado con la respuesta e non lo uno syn lo otro e lo pediese por testimonio.

Despues de lo qual el dicho don Abrahen Xarafi dixo en la dicha aljama que pues non avian querido conplir las dichas nuestras cartas que por virtud dellas 
los enplazava que en plazo para ante los dichos nuestros presidente e oydores para que dentro de çierto termino en ellas contenido paresçiesen ante ellos a dar razon por que non las querian conplir e con el testimonio del dicho enplazamiento el dicho don Abrahan Xarafi nuestro alcalde mayor vino e se presento en la dicha nuestra abdiençia ante los dichos nuestros presidente e oydores e presento una petiçion antellos en la que dixo /f. $4 \mathrm{r} /$ dixo que quel dicho su parte por merçed e previllejo que de nos tenia e por justos e derechos titulos que hemanaran de nos hera nuestro alcalde mayor de todas las aljamas de los moros de nuestros reynos e el como atal nuestro alcalde mayor e por los dichos previllejos e merçedes le perteneçia el juzgado e alcaldia mayor de todas las aljamas de nuestros reynos e el conoçimiento que de quales quier cabsas e quistiones, pleitos e debates que se acaesçiesen entre los dichos moros. E aviendose dado sentençia en favor del dicho su parte por el presidente e oydores de nuestra abdiençia por la qual le declararan por alcalde mayor de las dichas aljamas de nuestros reynos e le mandava que por tal le oviesen e conoçiesen, e seyendole dada (sobrescrito: nuestra) carta esecutoria del dicho serviçio e seyendo requeridos los partes contrarias que la obedeçiesen e conpliesen e que deviendolo asy fazer non la quisieron conplir, ante como non deviendo suplicaron de la dicha su merçed e carta esecutoria non aviendo razon nin cabsa para ello nin podiendo nin deviendo suplicar los partes contrarias e por que nos pidio e suplico que pronunçiasemos e declarasemos la dicha su merçed e carta esecutoria nuestra non aver avido lugar suplicaçion e que sy enbargo dello mandasemos a las partes contrarias conpliesen las dichas merçed e en /f. $4 \mathrm{v} /$ conpliendola que la obedeçiesen e toviesen por su alcalde mayor al dicho su parte segund e de la manera que se contenia en la merçed e sentençia que tenia el dicho su parte. $E$ que sy menester hera pronunçiasemos e declarasemos el dicho su parte ser alcalde mayor de la dicha aljama de moros de la dicha çibdad de Segovia e el dicho juzgado e alcaldia mayor perteneçiendole por merçed e previllejos e por sentençia dada en su favor condenando por su sentençia a la dicha aljama e a los moros della a que de aquí adelante (sobrescrito: le toviesen) por nuestro alcalde mayor e que paresçiesen antel e cunpliesen sus mandamientos, le acudiesen con todo lo otro devido e perteneçiente al dicho ofiçio de alcaldia mayor feziendo sobre todo el dicho su parte complimiento de justiçia, para lo quel ynploro nuestro real ofiçio e pedyo e protesto las cosas.

Contra lo qual Françisco de Santistevan en nombre e como procurador del aljama e moros de la çibdad de Segovia presento otra petiçion ante los dichos nuestros presidente e oydores en que dixo que los dichos sus partes non heran tenidos nin obligados a cosa alguna de lo en contrario pedido por lo siguiente: lo uno por quel dicho Pedro de Ariola e el dicho alfaqui en cuyo nombre pusiera la dicha demanda non fueron nin heran partes para la poner. Lo otro por que la dicha demanda non proçedia por ser como hera ynçierta e mal formada e ca- 
reçiente /f.5r/ de las cosas sustançiales de derecho. Lo otro, porque lo en ella contenido non hera verdadero, e negolo con animo de la contestaçion protestando de poner exen en ellaiones e defensyones en el termino de la ley. Lo otro, porque el dicho parte adversa non tenia tales previllejos como dezia nin era alcalde mayor nin tenia sentençia dada en su favor nin tal cosa sabian nin creyan los dichos sus partes, e que ante otras cosas nos suplicava le mandasemos que mostrase los previllejos sy algunos tenia pues que se fundava su demanda sobrellos, e protesto que fasta que los amostrase que a los dichos sus partes non corriese el termino de las execuçiones. Lo otro porque puesto que por el fuese dada alguna sentençia aquella seria dada contra otras personas e non contra los dichos sus partes, e que non les podia nin puede faser perjuysio alguno pues que ellos non pleytearan nin supieron del dicho pleito. Lo otro porque puesto quel dicho parte adversa se fuera tal alcalde mayor (tachado: dixo) que non se lo fue nin hera nin podria ser de los dichos sus partes por que de tiempo ynmemorial a esta parte ellos avian seydo e heran subjetos solamente a los justiçias de la dicha çibdad de Segovia e non al dicho parte adversa nin a otro alcalde mayor, e que en tal posesyon avie estado de tiempo ynmemorial a esta parte, viendolo e sabiendolo los tales alcaldes mayores que avian seydo desde el dicho tiempo aca, e non lo conpadeziendo antes feziendo muchos abtos /f. $5 \mathrm{v} /$ por donde perderian e perdieron los tales alcaldes mayore qualquier derecho o posesyon que toviesen para poder usar de la dicha alcaldia e que demas de aquello los dichos sus partes tenian previllejos usados e guardados sobrello. Lo otro porque a cabsa del dicho ofiçio de alcaldia mayor en la dicha çibdad de Segovia se syguieran tan grandes ynconvenyentes que por diversas vezes se perdiera el aljama de los moros de la dicha çibdad, e que por los reyes de gloriosa memoria que fueran destos reynos fuera mandado e determinado que puesto que oviese alcaldes mayores non usasen de juridiçion en la dicha çibdad de Segovia en el aljama de los moros della, la qual sentençia e determinaçion pasara en cosa juzgada. Porque nos pedia e suplicava que pronunçiasemos el dicho parte adversa non ser parte e su demanda non proçeder e desto (...)e que asolviesemos a los dichos sus partes de todo lo en contrario pedido e demandado e para en lo neçesario ynploro el nuestro real ofiçio (tachado: de vuestra alteza) e pidio e protesto las costas. E que como queria que en la dicha sentençia e carta esecutoria non hera neçesario suplicaçion que sy en caso que neçesario fuese dixo que escripto hera o podia ser este juysio de los dichos sus partes e firmandose en la suplicaçion por ellos ynterpuesta suplicava de la dicha sentençia y carta esecutoria e la dixo ninguna o do alguna contrs los dichos sus partes mucho ynjusta /f. $6 r /$ e agraviada por todas las razones de nulidad e agravios que la dicha sentençia e carta esecutoria e del proçeso del dicho pleito se podian e devian colegir que avian por espresados e por los contenidos en esta petiçion e por otras que entendia dever e alegar. Por que nos pedia e suplicava que en quanto a la dicha sentençia hera o podia ser en perjuysio de los 
dichos sus partes e neçesario les fuese suplicar della que la diesemos por ninguna e do alguna fuese que como ynjusta e agraviada la rebocasemos e para en lo neçesario ynploro nuestro real ofiçio e pidio e protesto las costas. Çerca de lo qual por amas las dichas partes fueron dichas e alegadas otras çiertas razones por sus petiçiones que ante los dichos nuestros presidente e oydores presentaron fasta tanto que concluyeron, e por los dichos nuestros presidente $e$ oydores fue avido el dicho pleyto por conçenso. E dieron en el sentençia en que fallaron que devian reçibir e reçibieron a amas las dichas partes e a cada una dellas conjuntamente a la prueva de lo por cada una dellas antellos dicho e alegado, a que de derecho devian de ser reçibidos a la prueva e provandoles aprovecharia salvo iure ynpetençian et non admitendorum. Para la qual prueva faser e para la traer e presentar antellos les dieron e asygnaron /f. $6 \mathrm{v} / c ̧ i e r t o$ termino dentro del qual por parte del dicho alfaqui fuera fecha çierta provança e pedida publicaçion della, e por los dichos nuestros presydente e oydores fue mandado faser e dar traslado a las partes e que en el termino de la ley dixiesen e alegasen de su derecho.

Despues de lo qual el dicho Pedro de Ariola en nombre del dicho alfaqui su parte presentara una petiçion ante los dichos nuestro presidente e oydores en que dixiera que por nos mandado ver e esaminar los testigos e provanças por su parte presentadas en el pleito quel dicho su parte avia e tratava ante los dichos nuestros presidente e oydores con el aljama de los moros de la çibdad de Segovia, se fallaria quel dicho alfaqui su parte que avia provado asaz conplidamente su yntençion tanto quanto provar devia e le convenia sobre lo que fuera reçibido a la prueva e que la dicha aljama parte contraria non provara su yntençion nin avia fecho diligençia alguna que les aprovechase e nos suplicava mandasemos dar la yntençion del dicho su parte por bien e conplidamente provada e la de la parte contraria por non provada, mandadndo faser en todo segund que por el dicho su parte estava pedido e suplicado. Para lo qual e en lo neçesario ynploro nuestro real ofiçio e presento çiertas escripturas de las quales /f. $7 \mathrm{r} /$ fuera mandado del traslado a la parte de la dicha aljama.

Despues de lo qual el dicho Pedro de Ariola en nombre del dicho su parte presentara otra petiçion en que dixiera que las (tachado: dichas) partes contrarias levaran termino perentorio para venir deziendo e concluyendo e que pues non dezian cosa alguna mandasemos aver e oviesemos el dicho pleito por concluso. e por los dichos nuestro presydente e oydores fue avido del dicho pleito por concluso. El qual por ellos visto dieron en el sentençia definitiva, en que fallaran quel dicho don Abrahen Xarafi provara bien e conplidamente su yntençion e todo aquello que provar deviera e dieron e pronunçiaron su yntençion por bien e conplidamente provada e quel aljama en ombres buenos moros de la çibdad de Segovia non provaran cosa alguna que les aprovechase, e dieron e pronunçiaron su yntençion por non provada, e que devian mandar e mandaron a 
los moros de la dicha aljama que viesen las cartas por nos dadas a el e las sentençias por ellos dadas sobre to susodicho e las guardasen e cunpliesen en todo e por todo segund que en ellas se contenia, e en guardandolas e conpliendolas le obedeçiesen e toviesen por su alcalde mayor e le dexasen e consentiesen a el e a quien su poder oviese (sobrescrito: usar) e exrçer el ofiçio del alcaldia mayor segund e como en las dichas cartas e sentençias se contenia e so las penas $/ f$. $7 \mathrm{v} /$ en ellas contenidas. E por que la dicha aljama letigaron mal e como non devian condenaronlos en las costas derechas fechas por parte del dicho don Abrahen Xarafi, la tasacion de las quoales en sy reservaron, e por su sentençia definitiva juzgando ansy lo pronunçiaron e mandaron que fuera dada la dicha sentençia por los dichos nuestros oydores en la villa de Valladolid a veynte e nueve dias de avril de mill e quatroçientos e noventa e un años, e fuera notificada firmada de los dichos nuestros oydores por el escrivano de la causa a Francisco de Santistevan, procurador de la dicha aljama.

E despues de lo qual el dicho Pedro de Ariola en nombre del dicho su parte paresçio ante los dichos nuestros presydente e oydores e dixo que como quier que la dicha sentençia fuera notificada al dicho Françisco de Santistevan, procurador de la dicha aljama, e que el termino en que pudiera suplicar della era ya pasado e non avia suplicado della, e que la dicha sentençia era ya pasada en cosa jusgada. E nos suplico e pidio por merçed le mandasemos dar nuestra carta esecutoria de la dicha sentençia (sobrescrito: e tasaçion de las costas) para que en todo fuese guardada e conplida e esecutada $E$ çerca dello de remedio con justiçia le mandasemos proveer como la nuestra merçed fuese. $E$ las costas en que los dichos nuestros presydente e oydores por la dicha su sentençia condenaron a la dicha aljama fueron $/ \mathrm{f}$. $8 \mathrm{r} /$ fueron por ellos tasadas e moderadas con juramento del dicho Pedro de Ariola segund que por menudo queda escriptas e asentadas en el proceso del dicho pleito en mill e dozientos e ochenta maravedis. Lo qual todo por los dichos nuestro presydente e oydores visto e proveyendo çerca dello acordaron de mandar dar e dieron esta nuestra carta para vos en la dicha razon, e nos tovimoslo por bien.

Por que vos mandamos que veades la dicha sentençia por los dichos nuestro presydente e oydores dada e pronunçiada en el dicho pleito e causa, que de suso va encorporada e la guardedes e cunplades e esecutedes e fagades guardar e conplir e esecutar en todo e por todo segund que en ella se contyene, (e) contra el tenor e forma della non vayades nin pasedes nin consyntades yr nin pasar en algund tiempo nin por alguna manera, e en guardandola e en conpliendola mandamos a la dicha aljama e ombres buenos moros de la dicha çibdad de Segovia que vean las dichas nuestras cartas por nos dadas al dicho don Abrahen Xarafi e las sentençias por los dichos nuestros presidente e oydores dadas e (sobrescrito: pronunçiadas) sobre razon del dicho ofiçio del alcaldia mayor e las guarden e cunplan en todo e por todo se- 
gund que en ellas se contiene, y en guardando e conpliendolas le obedescan e tengan por su alcalde mayor e le dexen e consyentan a el e a quien su poder oviere usar e exerçer el dicho ofiçio de alcaldia mayor segund e como en las dichas nuestras cartas sentençias se contiene so las penas en ellas contenidas.

E otrosy por esta nuestra carta mandamos a la dicha aljama e onbres buenos moros de la dicha çibdad de Segovia /f. 8v/ del dia que con esta nuestra carta fueren requeridos (sobrescrito: por parte del dicho don Abrahen Xarafi) fasta nueve dias primeros seguientes le den e paguen los dichos mill e dozientos e ochenta maravedis de las dichas costas en que asy por los dichos nuestros presidente e oydores fueron condenados (sobrescrito: e contra ellos fueron tasadas) segund dicho es. $E$ sy dentro del dicho termino non les dieren e pagaren los dichos mill e dozientos e ochenta maravedis de las dichas costas, mandamos a vos las dichas justiçias e juezes susodichos que fagades entrega e esecuçion en bienes de la dicha aljama sy los oviere e sy no mandamos a la dicha aljama e onbres buenos moros que dentro del dicho termino de los dichos nueve dias fagan repartimiento entre sy de los dichos mill e dozientos e ochenta maravedis de las dichas costas. $E$ fagades la esecuçion en las personas e bienes en que se fueren repartidos, e sy dentro del dicho termino de los dichos nueve dias non fizieren el dicho repartimiento, fasedes la dicha esecuçion en las personas e bienes de los regidores e ofiçiales de la dicha aljama e los bienes en que fizieredes la dicha esecuçion vendeldos e remataldos en publica almoneda segund fuero. E de los maravedis que valieren entregar e fazer pago al dicho don Abrahen Xarafi o a quien su poder oviere de los dichos mill e dozientos e ochenta maravedis de las dichas costas en que asy por los dichos nuestros presidente e oydores fueron condenados e contra ellos fueron tasados como derecho es. E sy bienes desenbargados non les fallarades para conplimiento del pago de lo que dicho es, prendeldes los cuerpos e teneldos presos e bien recabdados e lo non los dedes sueltos nin fiados fasta tanto que hayan fecho pago al dicho don Abrahen Xarafi de los dichos mill e dozientos e ochenta maravedis de las dichas costas con mas las otras costas que a su cabsa e culpa fizie en los cobrar. $E$ los unos nin los otros non fagades nin fagan ende al por alguna manera so pena de la nuestra merçed e de diez mill maravedis para la nuestra camara e corte. Dada en Valladolid a treynta dias de agosto de mill e quatroçientos e noventa e un años. Los dottores Martin de Avila e Juan de la Villa e liçençiado Garçia Fernandes de Roens oydores de la abdiençia de sus altesas la mandaron dar, escrivano Juan de Madrid. 